\title{
Weak proactive cognitive/motor brain control accounts for poor children's behavioral performance in speeded discrimination tasks
}

\author{
Quinzi $\mathrm{F}^{1}$, Perri RL ${ }^{2,4}$, Berchicci $\mathrm{M}^{2}$, Bianco $\mathrm{V}^{2}$, Pitzalis $\mathrm{S}^{1,2}$, Zeri $\mathrm{F}^{3} \&$ Di Russo $\mathrm{F}^{1,2}$
}

${ }^{1}$ RCCS Santa Lucia Foundation, Rome - Italy

${ }^{2}$ Department of Movement, Human and Health Sciences, University of Rome "Foro Italico", RomeItaly

${ }^{3}$ School of Life and Health Sciences, Aston University, Birmingham - UK.

4 University of Rome "Niccolò Cusano", Rome - Italy

\section{Corresponding author:}

Dr. Federico Quinzi, Ph.D.

IRCCS Santa Lucia Foundation, Rome - Italy

e-mail:fquinzi@libero.it 


\begin{abstract}
Background. Motor and inhibitory control rely on frontal cortex activity, which is known to reach full maturation only in late adolescence. The development of inhibitory control has been studied using event-related potentials (ERP), focusing on reactive processing (i.e. the N2 and the P3 components). Scarce information exists concerning pre-stimulus activity as that represented by the Bereinshafstpotential (BP) and by the prefrontal negativity (pN). Further, no literature exists concerning the post-stimulus components originating within the anterior insula (pN1, $\mathrm{pP} 1, \mathrm{pP} 2)$. This study aims at associating children performance with these motor-cognitive processing in frontal brain areas.
\end{abstract}

Methods. High-resolution EEG recordings were employed to measure ERPs from 18 children (12 years old) and 18 adults (28 years old) during a visuo-motor discriminative response task. Response time (RT), commission (CE) and omission errors, and RT variability were compared between groups. At brain level, two pre-stimulus (BP and $\mathrm{pN})$ and seven post-stimulus (P1; pN1; N1; pP1; N2; pP2; P3) ERP components were compared between groups. Results. Children showed slower and more variable RTs and poorer inhibition (higher CEs) than adults. At electrophysiological level, children presented smaller BP and pN. After stimulus onset, children showed lower amplitude of N1, pP1, P3, and pP2 components. The P1, pP1, N2 and P3 were delayed compared to adults.

Conclusions. Our results demonstrate that children are characterized by less intense task-related proactive activities in frontal cortex, which may account for subsequent poor and delayed reactive processing and, thus, for inaccurate and slow performance. 


\section{Introduction}

The human cognitive control includes many brain functions, such as attention, working memory, flexibility and inhibition necessary for individuals to interact with the surrounding environment. Inhibitory control has been defined as the ability to prevent undesired responses (Aron, Robbins, \& Poldrack, 2004). At a behavioral level, this ability is displayed when successfully stopping an ongoing response or withholding a dominant one to accomplish the required task (Davidson, Amso, Cruess Anderson, \& Diamond, 2006).

Several brain regions have been associated to an efficient inhibitory control, but the most accredited one is the right inferior frontal gyrus within the prefrontal cortex (PFC) (Aron, Robbins, \& Poldrack, 2004; Friedman, Nessler, Cycowicz, \& Horton, 2009; Perri, Berchicci, Spinelli, \& Di Russo, 2014; Vidal, Mills, Pang, \& Taylor, 2012). Compared to other brain regions, the development of the PFC appears to occur later in the growth process (Diamond, 1988; Sowell, 2004). Measures of myelination (Giedd et al., 1999), grey matter reduction (Sowell, Delis, Stiles, \& Jernigan, 2001), resting metabolism (Diamond, 2002) and brain activation (Bunge, Dudukovic, Thomason, Vaidya, \& Gabrieli, 2002; Casey et al., 1997; Vidal, Mills, Pang, \& Taylor, 2012; VijayaKumar et al., 2014) indicate that the PFC reaches its full maturation only in adult age. In fact, neuroimaging studies observed that children failed to activate the right ventrolateral PFC during visual discriminative response tasks (DRTs) (Bunge, Dudukovic, Thomason, Vaidya, \& Gabrieli, 2002), or adopted a different strategy to inhibit the motor response, consisting in the activation of the left middle frontal and pre-central gyri (Vidal, Mills, Pang, \& Taylor, 2012); but see Casey et al., 1997 and Luna et al., 2001 for different results). The different functional neuroimaging profile observed in children likely accounts for their poorer behavioral performance observed in children when compared to adults (Casey et al., 1997; Ciesielski, Harris, \& Cofer, 2004; Jonkman, 2006). 
The development of brain functions has been widely studied also using electrophysiological methods, such as event-related potentials (ERPs), which allow measures of the magnitude (amplitude), speed (latency) and the time-course of cognitive processing. Compared to adults, children demonstrate a general tendency towards larger and slower ERPs, with the former likely accounted by lower skull thickness and density (Holcomb, Coffey, \& Neville, 1992; Knott, Hazony, Karafa, \& Koltai, 2004) and higher synaptic density (Huttenlocher, 1979) of children, and the latter explained by the incomplete myelination process (Barry \& Blasio, 2015; Barry, De Blasio, \& Borchard, 2014; Ciesielski, Harris, \& Cofer, 2004; Giedd et al., 1999; Johnstone et al., 2007; Lamm, Zelazo, \& Lewis, 2006).

Most of the existing ERP studies in children cognition focused on two post-stimulus ERP components: the N2 and the P3, either during auditory (Barry \& Blasio, 2015; Barry, De Blasio, \& Borchard, 2014; Ciesielski, Harris, \& Cofer, 2004) or visual tasks (Ciesielski, Harris, \& Cofer, 2004; Davis, Bruce, Snyder, \& Nelson, 2003; Jonkman, 2006; Jonkman, Lansbergen, \& Stauder, 2003; Lamm, Zelazo, \& Lewis, 2006; Okazaki et al., 2004); for a review see Segalowitz, Santesso, \& Jetha, 2010). In children, the amplitude of the N2 was related to individual differences in inhibitory control (Barry \& Blasio, 2015), with a more frontal distribution compared to adults (Barry \& Blasio, 2015; Ciesielski, Harris, \& Cofer, 2004; Jonkman, Lansbergen, \& Stauder, 2003). Cross-sectional studies showed that N2 amplitude decreases with age (Davis, Bruce, Snyder, \& Nelson, 2003; Jonkman, Lansbergen, \& Stauder, 2003), reflecting developmental changes in cognitive control (Lamm, Zelazo, \& Lewis, 2006). The later P3 component was associated with decision/inhibition processes (Johnstone et al., 2007; Jonkman, Lansbergen, \& Stauder, 2003; Polich, 2007); however, due to its late timing, concomitant or following the response, this association seems rather unlikely, whereas an association with the "reset" or task closure processes seems more plausible (see Falkenstein, Hoormann, \& Hohnsbein, 1999).

Notwithstanding the large body of research on the developmental modifications in cognitive control, existing ERPs evidence focused primarily on some of the post-stimulus components, providing a 
somehow limited view of the entire decision-making processes. Indeed, several ERP studies from our research group (Berchicci, Lucci, Perri, Spinelli, \& Di Russo, 2014; Berchicci, Lucci, Pesce, Spinelli, \& Di Russo, 2012; Berchicci, Spinelli, \& Di Russo, 2016; Bianco, Berchicci, Perri, Quinzi, \& Di Russo, 2017; Bianco, Di Russo, Perri, \& Berchicci, 2017; Di Russo et al., 2016; Perri, Berchicci, Lucci, Spinelli, \& Di Russo, 2015a, 2016; Perri, Berchicci, Spinelli, \& Di Russo, 2014; Sulpizio et al., 2017) revealed that the entire decision-making processes is characterized not only by the well-studied post-stimulus components, but also by two pre-stimulus components and three recently discovered post-stimulus components. Despite the importance of brain preparatory activity in the decision processing, only few studies in children focused on the pre-stimulus brain activity. Some of these studies used the contingent negative variation (CNV) paradigm (Jonkman, 2006; Jonkman, Lansbergen, \& Stauder, 2003), showing reduced response preparation (Jonkman, 2006) in young children compared to older children and adults, and comparable preparatory brain activities between these latter age groups (Jonkman, Lansbergen, \& Stauder, 2003). Berchicci et al. (2015) investigated the effect of physical fitness on motor and cognitive preparation in children represented respectively by the Bereitschaftspotential (BP) and by the prefrontal negativity $(\mathrm{pN})$ during a flanker task showing lager cognitive preparation in high-fit children. The BP, is a slow-rising negativity originating in the supplementary and cingulate motor cortex (Di Russo et al., 2017; Shibasaki \& Hallett, 2006) and reflecting motor preparation whereas the $\mathrm{pN}$, is another slow rising negativity detected on prefrontal sites concomitantly to the BP (Berchicci, Lucci, Perri, Spinelli, \& Di Russo, 2014; Berchicci, Lucci, Pesce, Spinelli, \& Di Russo, 2012; Berchicci, Spinelli, \& Di Russo, 2016; Perri, Berchicci, Lucci, Spinelli, \& Di Russo, 2015a, 2016; Perri, Berchicci, Spinelli, \& Di Russo, 2014). It has been related to proactive cognitive preparation (Di Russo et al., 2016), in particular to the inhibitory control (Bianco, Berchicci, Perri, Quinzi, \& Di Russo, 2017; Bianco, Di Russo, Perri, \& Berchicci, 2017), and its origin has been localized in the inferior frontal gyrus (Di Russo et al., 2016; Sulpizio et al., 2017). 
In visuo-motor tasks after stimulus onset, in addition to the well documented sensorial (P1 and N1) and endogenous (N2 and the P3) components, three more components have been identified: the prefrontal $\mathrm{N} 1, \mathrm{P} 1$ and $\mathrm{P} 2$ (pN1, pP1 and pP2 respectively) peaking between 110 and $300 \mathrm{~ms}$ after the stimulus onset and localized in the rostral part of anterior insula (Di Russo et al., 2016; Sulpizio et al., 2017). While the pN1 and pP1 are related to top-down perceptual processing associated with stimulus physical salience and awareness and sensory-motor integration respectively (Perri et al., 2018; Perri, Berchicci, Bianco, Spinelli, \& Di Russo, 2018; Perri \& Di Russo, 2017; Sanchez-Lopez et al., 2017), the pP2 has been associated with evidence accumulation process, that is the efficacy of the stimulus-response mapping (Berchicci, Spinelli, \& Di Russo, 2016; Darriba \& Waszak, 2018; Di Rollo et al., 2016; Di Russo et al., 2016; Perri, Berchicci, Lucci, Spinelli, \& Di Russo, 2015b, 2015a, 2016; Perri \& Di Russo, 2017). These anterior insular ERP components were recently characterized by the present research group; however, in the past, several research groups found that anterior ERP components were generically localized in frontal areas (Foxe \& Simpson, 2002; Potts, Liotti, Tucker, \& Posner, 1996).

To the best of our knowledge, these latter prefrontal components ( $\mathrm{pN} 1, \mathrm{pP} 1$ and $\mathrm{pP} 2)$ have never been investigated in children so far.

In the present study, ERP and behavioral measures were recorded during the whole preparation, perception and action phases of a visual DRT, allowing to accurately identify the time-course of the underlying cognitive processes. Specifically, we investigated the neural correlates of proactive inhibitory control and decision-making in a group of preadolescent children, and compared them with a group of young adults, providing a comprehensive picture of the differences of the entire decision-making processes between the two age groups.

Consistent with previous literature on this topic (e.g. Casey et al., 1997; Ciesielski, Harris, \& Cofer, 2004; Jonkman, Lansbergen, \& Stauder, 2003), we expect that, at the behavioral level, children will present slower response times and higher commission error rate. At the neurophysiological level, this 
pattern might be associated with later and reduced ERPs when compared to adults. We hypothesize that this scenario could be subtended by an immature contribution of premotor and prefrontal regions, such as reduced cognitive preparation in the younger participants.

\section{Methods}

\section{Participants}

Thirty-six healthy individuals volunteered to participate in this study. Participants were divided in two groups depending on their age; a group of 18 children (Age: 9-14 years Mean: $11.6 \pm 1.4$ years; 12 females), and a group of 18 adults (Age: 21-35 years Mean: 28.2 \pm 9.6 years; 10 females). Participants had a normal or corrected to normal vision, were free from neurological disorders and were right handed. Santa Lucia Foundation ethical committee approval was obtained for this study. Adult participants and children' legal guardians signed a written informed consent after a thorough explanation of the study.

\section{Procedure}

The experiment was carried out in a sound attenuated, dimly lit room. Participants were seated in front of a computer screen at $114 \mathrm{~cm}$ distance; their right arm was comfortably positioned on the armrest to allow them to push with the index finger of their right hand on a computer keyboard. In a randomized, equally probable order, four stimuli were presented on the computer screen for $250 \mathrm{~ms}$ (Contrast $80 \%$ ). Two of them were defined as Go stimuli and the other two were defined as No-go stimuli (please see Perri, Berchicci, Lucci, Spinelli, \& Di Russo, 2016 for further details). The inter stimulus interval randomly varied from 1 to $2 \mathrm{~s}$ to avoid the possibility for the participants to easily predict the stimulus onset and to avoid overlapping of ERP activity. Participants were asked to press the keyboard button as quickly as possible when Go stimuli were presented and to withhold their response when No-go stimuli were shown. For the entire duration of the test, accuracy and speed were equally encouraged. Stimuli 
were presented in runs lasting 2 minutes each. Adults performed ten runs (400 Go and 400 No-go trials) whereas children endured the task for six to eight runs (240-320 Go and 240-320 No-go trials). After each run, volunteers were granted 1-2 min rest.

\section{Data Recording and Processing}

EEG signals were recorded using two BrainAmp ${ }^{\mathrm{TM}}$ amplifiers and the Recorder 1.2 software and were analyzed using the Analyzer 2.1 software (Brain-Products GmbH, Munich, Germany). A total of 64 nonpolarizable sintered $\mathrm{Ag} / \mathrm{AgCl}$ electrode electrodes were placed on the participants scalp according to the international 10-10 system and referenced to the left mastoid. An electrode placed below the right eye and referenced to Fp1 recorded vertical electrooculogram (EOG), whereas horizontal EOG was recorded from an electrode on the left external canthi and referenced to that on below the right eye. EEG and EOG were digitized at $250 \mathrm{~Hz}$, amplified and band pass filtered $(0.01-80 \mathrm{~Hz})$. Additionally, a $50 \mathrm{~Hz}$ notch filter was applied to the recorded signals. For all participants, impedance was kept below $5 \mathrm{k} \Omega$. EEG and EOG were stored for further analysis.

EEG continuous recordings were visually inspected to detect the presence of gross artifacts. Independent component analysis (ICA) "Infomax" algorithm was applied to correct EOG artifacts. 12.8 (6-8) components were discarded in the children group whereas 10 (6.2) in the adult group; no significant difference $(\mathrm{p}=0.09)$ between the two groups was observed in the number of discarded components. The EOG-corrected EEG signals were separately (Go and No-go stimuli) segmented in stimulus locked epochs of $2000 \mathrm{~ms}$, starting from -1100 to $900 \mathrm{~ms}$ with time-zero considered as the stimulus onset (for some similar studies investigating pre-stimulus ERP, please see Berchicci, Lucci, Perri, Spinelli, \& Di Russo, 2014; Perri, Berchicci, Lucci, Spinelli, \& Di Russo, 2015a, 2016; Perri, Berchicci, Spinelli, \& Di Russo, 2014). Prior to signal averaging, the artifact rejection was performed to discard epochs contaminated by muscular activity or movement related artifacts. For all participants, epochs containing 
amplitudes larger than $\pm 50 \mu \mathrm{V}$ were systematically discarded. The percentage of removed signal was $0.7 \% \pm 0.8$ for children and $0.4 \% \pm 0.5$ for adults. This percentage was not significantly different between the two groups $(p=0.19)$. Afterwards, for each participant Go and No-go epochs were separately averaged. Moreover, to further reduce high-frequency noise, an IIR low-pass filter (25 Hz; 24db/oct) was applied to the individual grand averages.

To investigate pre-stimulus ERP, Go and No-go trials were averaged and baseline-corrected during the initial $200 \mathrm{~ms}$ of the epoch (from 1100 to $900 \mathrm{~ms}$ before stimulus onset). For the analysis of post-stimulus ERPs, the baseline was computed in the interval ranging from -200 ms to stimulus onset.

According to literature, the $\mathrm{BP}$ was quantified as the average activity over medial central $(\mathrm{Cz}$ and $\mathrm{CPz})$ sites in three intervals of time preceding the stimulus presentation. In particular, the interval ranging from -900 to $-600 \mathrm{~ms}$ was defined as early BP; while from -600 to $-300 \mathrm{~ms}$ it was defined as mid BP; the interval ranging from $-300 \mathrm{~ms}$ to the stimulus presentation was defined as late BP. Similarly, the pN was computed bilaterally in the same intervals over prefrontal sites (Fp1, Fp2 and AFz).

Peak amplitudes and latencies of post-stimulus ERP components were computed for Go and No-go conditions separately over the following electrodes and time-windows based on previous literature (e.g. Berchicci, Spinelli, \& Di Russo, 2016). Peak latency and amplitude of the P1 and the N1 components were computed over PO7 and PO8 electrodes in the 80-150ms and 150-250ms intervals, respectively. Peak latency and amplitude of the N2 component were computed over medial central-frontal electrodes (Cz, FCz and Fz) from 150-350ms after stimulus onset. Peak latency and amplitude of the P3 component were computed over medial central-parietal electrodes (Cz, CPz, and Pz) from 300-800 ms. Peak latency and amplitude of the pN1 and pP1 components were computed over prefrontal sites (Fp1, Fp2 and AFz) in the 80-180 ms and 150-250 ms interval, respectively. In addition, to highlight the amplitude modulation of the pP2 component between Go and No-go conditions, for each participant, differential waves over prefrontal derivations were computed by subtracting No-go from the Go ERP, as previously 
described in Perri and colleagues (2014). The individual differential waves were band pass filtered (IIR filter, $0.5-15 \mathrm{~Hz}, 24 \mathrm{db} / \mathrm{oct})$ and the differential prefrontal positivity (dpP2) was identified as the positive peak in the interval from 200 to 400 ms post-stimulus over AFz electrodes.

\section{ERPs Normalization}

To account for the well-documented, anatomy-related, amplitude differences between children and adults, a normalization process was carried out on ERPs amplitude (hereinafter referred to as "corrected"). In detail, for each participant and for each condition (Go and No-go stimuli), the peak amplitude of a given component (e.g. BP, pN, P1, N1, pN1, pP1, dpP2, N2, P3) was divided by the maximal amplitude of the P1 recorded over parieto-occipital electrodes (PO7, PO8, PO3, PO4, O1, and O2). This normalization method allowed us to maintain the original component polarity. The choice to adopt such a normalization process and to use the P1 amplitude as a reference for the other ERP components can be justified on the basis of the consideration that the cortical generators of the $\mathrm{P} 1$, that is the occipital extrastriate visual cortex (Di Russo et al., 2016; Sulpizio et al., 2017), is thought to reach a mature condition within 10 years of age, prior to other cortical areas as frontal cortex (Deoni, Dean, Remer, Dirks, \& O’Muircheartaigh, 2015). Breaking down the uniform bias across present age groups explained by differences in the skull anatomy and synaptic density, this normalization should allow to detect any other group difference in cognitive processing.

\section{Behavioral Data}

For each participant, response accuracy was measured computing the percentage of Omission errors (\%OE; response withheld when a Go stimulus was presented) and Commission errors (\%CE; response to No-go stimuli). For each stimulus, the response time (RT) was computed as the time elapsed from stimulus onset and correct response (i.e. button press for Go stimuli). Individual RT was computed as the median of all single trial across correct responses. The group RT was calculated as mean value. The 
consistency of the RT was computed by means of the intra-individual coefficient of variation (ICV), calculated as the ratio between SD and mean RT.

\section{Statistical Analysis}

All the statistical procedures have been performed using the SPSS statistical package (SPSS version 20). For all statistical tests, the null hypothesis was rejected with $\alpha<0.05$. A one-way analysis of variance (ANOVA) was employed to test the effect of group [Children; Adults] on behavioral data (RT; ICV; $\% \mathrm{OE} ; \% \mathrm{CE})$. For all of the ERP components, statistical analysis was carried out both on original and corrected ERPs amplitudes. The effects of group [Children; Adults], condition [Go; No-go], and electrode $[\mathrm{Cz} ; \mathrm{CPz}]$ on the BP were analyzed by means of a 2 x 2 x 2 ANOVA for early, mid and late BP. Similarly, the effects of group [Children; Adults], condition [Go; No-go], and electrode [Fp1; Fp2; $\mathrm{AFz}]$ on the $\mathrm{pN}$ component were analyzed by means of a $2 \times 2 \times 3$ ANOVA for the three intervals defined for the BP. The effects of group [Children; Adults], condition [Go; No-go], and electrode [PO7; PO8] on peak latency and amplitude of P1 and N1 components were analyzed by means of a 2 x 2 x 2 ANOVA. A 2 × 2 × 3 ANOVA was employed to test the effect of group, condition and electrode [Fp1; Fp2; AFz] on the $\mathrm{pN} 1$ and the pP1 peak latency and amplitude. Group, condition and electrode [Cz; FCz; Fz] effects in peak latency and amplitude of the N2 component were analyzed by means of a 2 × 2 × 3 ANOVA. Whereas, group, condition and electrode $[\mathrm{Cz} ; \mathrm{CPz} ; \mathrm{Pz}]$ effects in peak latency and amplitude of the P3 were analyzed by means of a 2 × 2 × 3 ANOVA. One-way ANOVA was employed to test the effect of group on the amplitude and latency of the dpP2 component. Tukey post-hoc test was performed when appropriate. To control for the possible effect of the different number of the trials per condition between groups (about 300 in children and 400 in adults), we recomputed the adults' grand average using the first 300 trials per condition, as for the children group. The results of the statistical analysis between groups did not change, confirming the results stability. 
To verify for the presence of a relationship between ERP components and behavioral data, for each group, Pearson's product moment correlations were performed between RT, \%OE, \% CE and corrected ERP components amplitude.

\section{Results}

\section{Behavioral Data}

Behavioral data of the two groups and statistics are presented in Table 1. Compared to adults, children exhibited slower RTs, higher \%CE and higher ICV. Conversely, no difference emerged between the two groups in \%OE. In addition, we calculated the post-error slowing (RT in correct trials both after correct and incorrect trials). Statistical analysis showed lack of effect in children (6 ms slowing, from $563 \pm 89$ $\mathrm{ms}$ to $569 \pm 90 \mathrm{~ms} ; \mathrm{p}=0.74$ ), whereas it was present in adults, showing a significant $29 \mathrm{~ms}$ slowing (from $429 \pm 49 \mathrm{~ms}$ to $456 \pm 68 \mathrm{~ms}, \mathrm{p}=0.001)$, However, the average number of correct go-trials after incorrect trials was relatively low in both groups (12 in children and 10 in adults).

Table 1. Behavioral data and statistics $(* * \mathrm{p}<0.01$, ns: not significant $)$

\begin{tabular}{lccc}
\hline & Children & Adults & \\
& mean $(S D)$ & mean $(S D)$ & \\
\hline RT [ms] & $563(86)$ & $424(49)$ & $34.8^{* *}$ \\
ICV & $0.187(0.035)$ & $0.153(0.020)$ & $12.2^{* *}$ \\
CE [\%] & $13.21(9.43)$ & $4.52(3.88)$ & $13.1^{* *}$ \\
Om [\%] & $2.29(4.24)$ & $0.63(1.15)$ & $2.5 ; \mathrm{ns}$ \\
\hline
\end{tabular}




\section{ERP data}

Figure 1a shows the average of Go and No-go trials to focus on the pre-stimulus ERP components $\mathrm{pN}$ and BP. In both groups, the BP and the $\mathrm{pN}$ are clearly visible. When uncorrected data are considered, Children (red lines) showed larger and earlier activity than adults (black lines), but after the correction (green lines) it became clearly smaller than adults. The pN and the BP initiated at approximately $900 \mathrm{~ms}$ in children and at $750 \mathrm{~ms}$ in adults. Figure 1b, shows the topographical distribution of the BP and the $\mathrm{pN}$ components (uncorrected ERP amplitudes). A similar scalp distribution of the two components can be observed, even though the $\mathrm{pN}$ was more anterior and the BP more posterior in children than in adults. In addition, a clear presence of these preparatory components in the earlier interval (-900/-600 ms) is visible in children. 



\section{Figure 1}

Figure 2 shows the post-stimulus ERP components for Go (continuous lines) and No-go (dashed lines) trials of both groups plus the corrected ERP of children (the color code is the same of Figure 1). Figure 
3 shows the topographical distribution of the relative components (original ERP amplitude). After stimulus onset, the P1 peaking at 100-130 ms and the N1 at about $200 \mathrm{~ms}$ can be observed in both groups, regardless the condition (Go and No-go). The P1 and the N1 components typically peak at bilateral parietal-occipital electrodes (PO7 and PO8) in adults; although the bilateral topographical distribution of the N1 is observed in children too, the P1 showed a more medial distribution over occipital areas. At medial prefrontal electrodes, the $\mathrm{pN} 1$ peaking from 100 to $135 \mathrm{~ms}$ and the $\mathrm{pP} 1$ at $180-210 \mathrm{~ms}$ can be observed in both groups and conditions, even though the pP1 focused more posteriorly in children. The N2 peaked at medial central-frontal sites between 250 and $350 \mathrm{~ms}$ in both groups. The P2 that is usually not visible in DRTs because of the concomitant central negativities (e.g. Berchicci, Spinelli, \& Di Russo, 2016), was instead clearly present in children with its typical medial parietal-occipital distribution. In adults, the P3 peaked at medial central and central-parietal $(\mathrm{Cz}$ and $\mathrm{CPz})$ sites between 400 and $450 \mathrm{~ms}$ and showed its typical No-go anteriorization, which was less marked in children. The prefrontal pP2 was clearly visible in adults between 200 and $400 \mathrm{~ms}$, especially for the Go condition. In children, this positivity was not present, and it was replaced by a strong negativity. However, being this activity consistently less negative in the Go than No-go condition, differential waveforms were computed (Go minus No-Go) to unmask it (Figure 4a). In adults, a positive peak can be clearly identified in the differential wave peaking over medial prefrontal areas at approximately $320 \mathrm{~ms}$, the dpP2; a component that previous authors named differential prefrontal positivity (dpP; Perri, Berchicci, Spinelli, \& Di Russo, 2014). Compared to adults, children showed a similar scalp distribution of the dpP2. In children, this component seems to be delayed in time with respect to adults (although the statistical significance was not reached). Differential ERP also shows the P3 effect over medial parietal areas. 


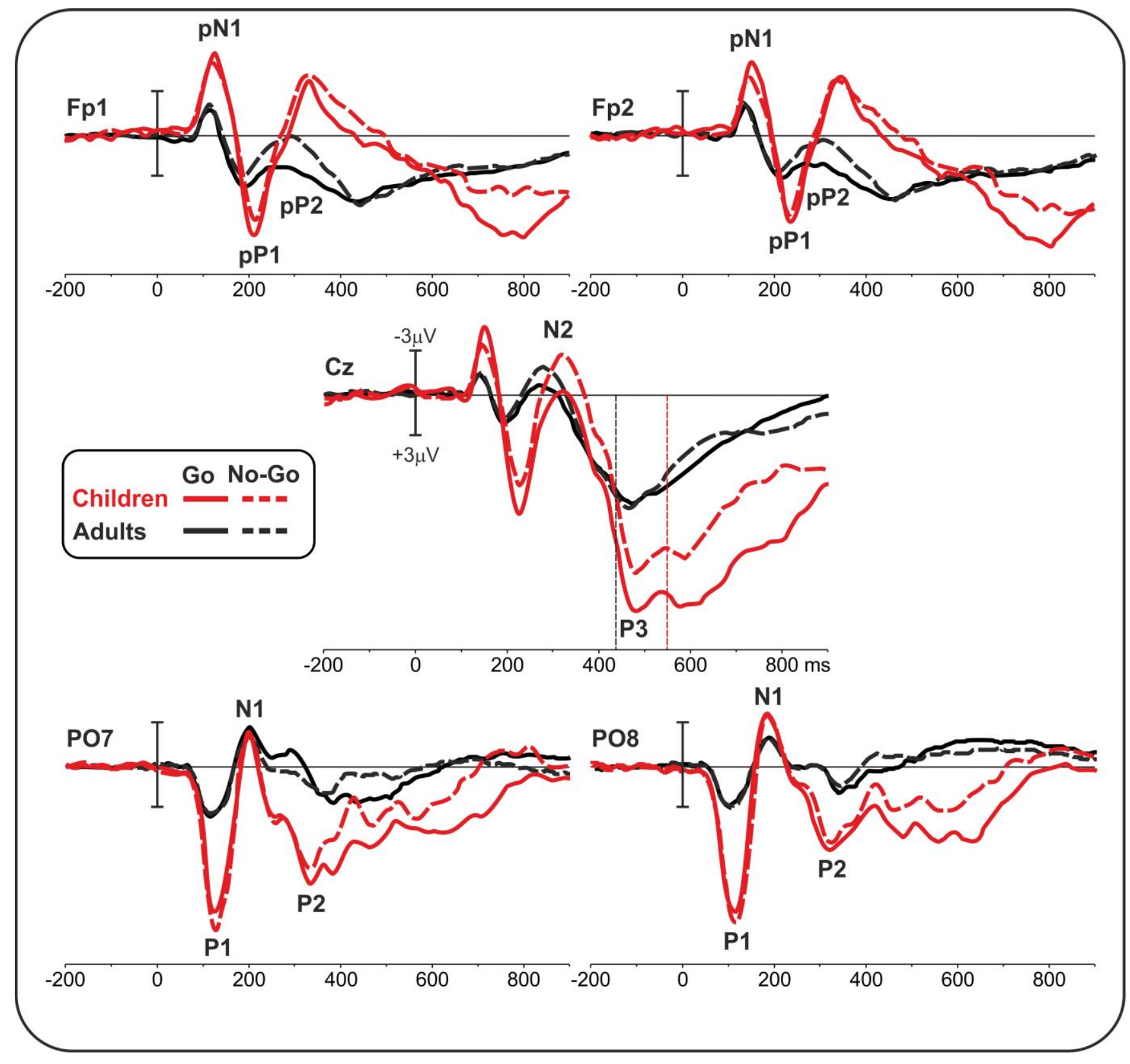

Figure 2 

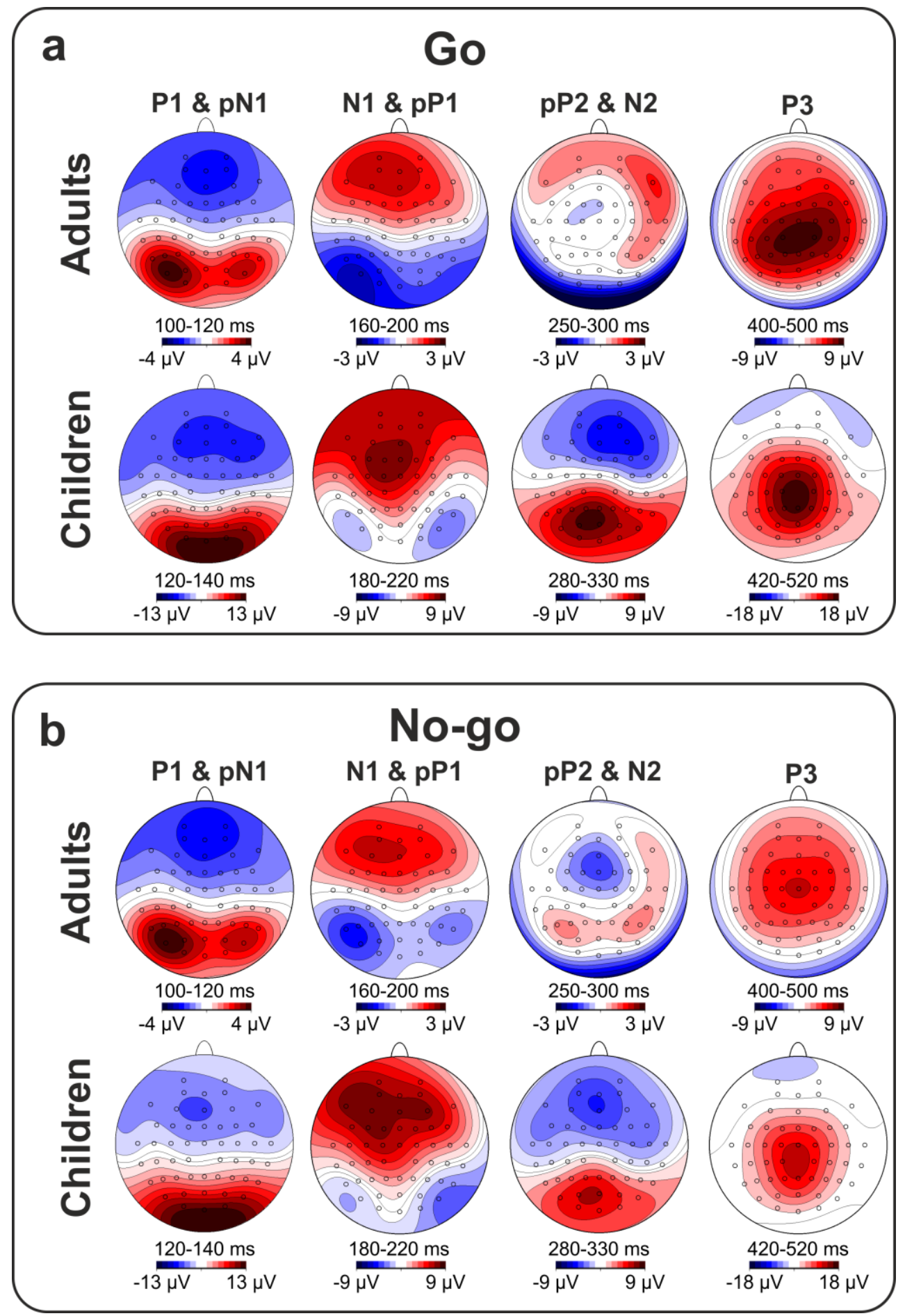

Figure 3 


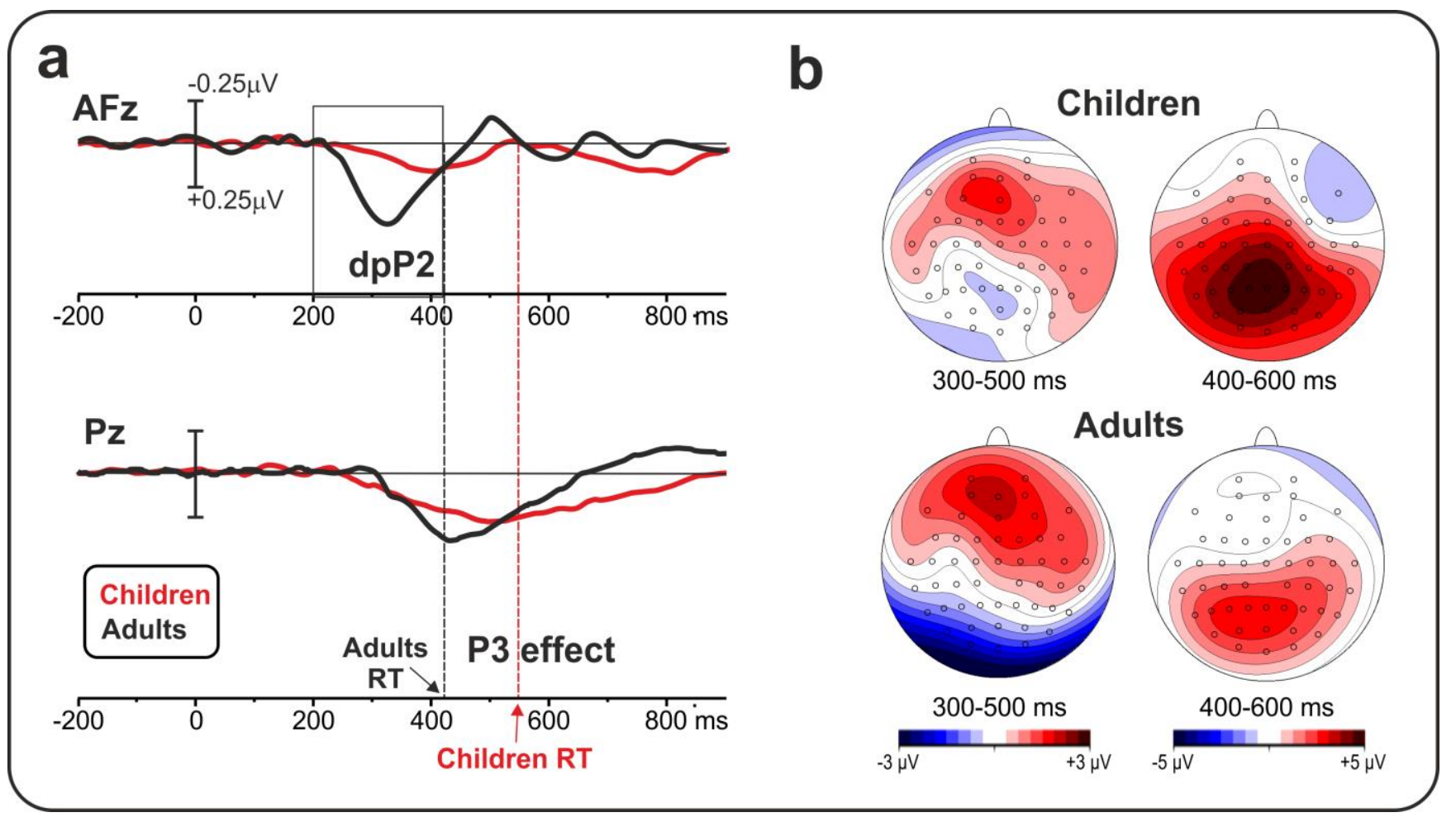

Figure 4

\section{Statistical results}

\section{Pre-stimulus components}

Statistics on corrected and un-corrected pre-stimulus components is reported in Table 2. Children exhibited larger uncorrected early BP (from -900 to $-600 \mathrm{~ms}$ ) compared to adults. No significant differences were observed between the two groups for uncorrected mid (from -600 to $300 \mathrm{~ms}$ ) and late BP (from -300 to $0 \mathrm{~ms}$ ). No significant effect of condition and electrode, and no significant group $\mathrm{x}$ condition and group x electrode interactions were observed in any interval. Children exhibited larger uncorrected $\mathrm{pN}$ with respect to adults in the early and mid-intervals (-900/300 ms). No significant effect of condition and electrode were observed for this component, as well as no significant interactions emerged in the considered intervals. 
When the BP amplitude was corrected, groups exhibited no difference in the early BP (-900/-600 ms), whereas in children BP amplitude was lower than adults in the mid and late intervals (-600/0 ms). In addition, children showed lower corrected $\mathrm{pN}$ amplitude only in the late interval (300 ms preceding the stimulus), whereas no difference between groups was observed in the early and mid-intervals.

Table 2. Pre-stimulus ERP component amplitude (mean and SD) and statistics $\left({ }^{*} p<0.05\right.$, ${ }^{* *} p<0.01$, ns: not significant) for original and corrected data (mean and SD).

\begin{tabular}{|c|c|c|c|c|c|c|c|}
\hline \multicolumn{2}{|c|}{ Interval (ms) } & \multicolumn{2}{|c|}{$-900 /-600$} & \multicolumn{2}{|c|}{$-600 /-300$} & \multicolumn{2}{|c|}{$-300 / 0$} \\
\hline \multirow{4}{*}{ BP } & Child & $-1.30(1.40)$ & \multirow{2}{*}{$F=17.6^{* *}$} & $-2.41(2.85)$ & \multirow{2}{*}{$F=1.6 ; \mathrm{ns}$} & $-2.91(3.86)$ & \multirow{2}{*}{$F<1 ; \mathrm{ns}$} \\
\hline & Adult & $-0.23(0.57)$ & & $-1.74(1.26)$ & & $-2.75(1.81)$ & \\
\hline & Child (Corrected) & $-0.07(0.08)$ & \multirow{2}{*}{$F=1.1 ; \mathrm{ns}$} & $-0.13(0.18)$ & \multirow{2}{*}{$F=8.7 * *$} & $-0.15(0.22)$ & \multirow{2}{*}{$F=17.8^{* *}$} \\
\hline & Adult (Corrected) & $-0.04(0.13)$ & & $-0.31(0.30)$ & & $-0.49(0.41)$ & \\
\hline \multirow{4}{*}{$\mathbf{p N}$} & Child & $-0.86(1.32)$ & \multirow{2}{*}{$F=15.3 * *$} & $-1.74(2.49)$ & \multirow{2}{*}{$F=3.2^{*}$} & $-2.24(3.14)$ & \multirow{2}{*}{$F=1.1 ; \mathrm{ns}$} \\
\hline & Adult & $-0.10(0.46)$ & & $-1.01(1.59)$ & & $-1.65(2.61)$ & \\
\hline & Child (Corrected) & $-0.06(0.11)$ & \multirow{2}{*}{$F=2.9 ; \mathrm{ns}$} & $-0.11(0.21)$ & \multirow{2}{*}{$F=2.9 ; \mathrm{ns}$} & $-0.14(0.22)$ & \multirow{2}{*}{$F=4.8^{*}$} \\
\hline & Adult (Corrected) & $-0.03(0.08)$ & & $-0.24(0.50)$ & & $-0.41(0.86)$ & \\
\hline
\end{tabular}

\section{Post-stimulus components}

All the original post-stimulus components in children presented larger amplitudes (see Table 4, supplementary material). In the following paragraphs, only the corrected ERP amplitudes will be presented and discussed.

Statistics on post-stimulus components latency and corrected amplitude are reported in Table 3 . As it can be seen, with the notable exception of $\mathrm{pN} 1, \mathrm{~N} 1$ and $\mathrm{dpP} 2$, in children all the post-stimulus components presented a delayed peak compared to adults. In addition, a significant interaction was observed for $\mathrm{pN} 1$ latency $\left(F_{1,34}=7.5, p=0.007\right)$, with children showing delayed peaks in the Go conditions with respect to adults. 
Children exhibited smaller corrected N1 when compared to adults, while no effect of condition was observed for the corrected N1 amplitude.

When the pN1 and pP1 amplitudes were corrected (Table3), a tendency $(p=0.065)$ toward smaller pN1 amplitude in children was observed. Conversely, a clear main effect of group was observed for the corrected pP1, with children showing smaller amplitudes. For both components, no significant effect of condition was observed, as well as no significant interaction for the corrected amplitudes.

The statistical analysis performed on the corrected N2 amplitude showed no significant effect of group, while in both groups the No-go condition presented larger amplitudes than Go.

When corrected, the P3 amplitude was larger in adults than children, while no effect of condition was observed for this component. Finally, once corrected, a significant effect of group was also observed, with adults presenting enhanced dpP2. 
Table 3. Corrected post-stimulus ERP component amplitude (Amp), latency (Lat) and statistics $\left({ }^{*} p<0.05\right.$, $* * p<0.01$, ns: not significant). Data are mean and SD.

\begin{tabular}{|c|c|c|c|c|c|c|c|}
\hline & & & Group & & & Condition & \\
\hline \multirow{4}{*}{ P1 } & \multirow{2}{*}{ Amp } & Child & $0.63(0.23)$ & \multirow{2}{*}{$F<1 ;$ ns } & Go & $0.63(0.26)$ & \multirow{2}{*}{$F<1 ; \mathrm{ns}$} \\
\hline & & Adult & $0.68(0.28)$ & & No-go & $0.67(0.25)$ & \\
\hline & \multirow{2}{*}{ Lat } & Child & $124(17)$ & \multirow{2}{*}{$F=4.9 *$} & Go & 118 (19) & \multirow{2}{*}{$F<1 ; \mathrm{ns}$} \\
\hline & & Adult & $116(21)$ & & No-go & $121(20)$ & \\
\hline \multirow{4}{*}{ pN1 } & \multirow{2}{*}{ Amp } & Child & $-0.36(0.19)$ & \multirow{2}{*}{$F=3.4 ; p=.06^{*}$} & Go & $-0.38(0.26)$ & \multirow{2}{*}{$F<1 ; \mathrm{ns}$} \\
\hline & & Adult & $-0.44(0.40)$ & & No-go & $-0.42(0.36)$ & \\
\hline & \multirow{2}{*}{ Lat } & Child & $127(25)$ & \multirow{2}{*}{$F=1.7 ; \mathrm{ns}$} & Go & $124(21)$ & \multirow{2}{*}{$F<1 ;$ ns } \\
\hline & & Adult & $122(24)$ & & No-go & $125(28)$ & \\
\hline \multirow{4}{*}{ N1 } & \multirow{2}{*}{ Amp } & Child & $-0.33(0.38)$ & \multirow{2}{*}{$F=8.2 * *$} & Go & $-0.51(0.68)$ & \multirow{2}{*}{$F<1 ;$ ns } \\
\hline & & Adult & $-0.66(0.87)$ & & No-go & $-0.48(0.69)$ & \\
\hline & \multirow{2}{*}{ Lat } & Child & $204(26)$ & \multirow{2}{*}{$F=3.0 ; \mathrm{ns}$} & Go & $201(26)$ & \multirow{2}{*}{$F<1 ;$ ns } \\
\hline & & Adult & 196 (29) & & No-go & $200(30)$ & \\
\hline \multirow{4}{*}{ pP1 } & \multirow{2}{*}{ Amp } & Child & $0.36(0.24)$ & \multirow{2}{*}{$F=14.3 * *$} & Go & $0.60(1.01)$ & \multirow{2}{*}{$F<1 ; \mathrm{ns}$} \\
\hline & & Adult & $0.83(1.24)$ & & No-go & $0.59(0.83)$ & \\
\hline & \multirow{2}{*}{ Lat } & Child & $207(25)$ & \multirow{2}{*}{$F=5.2 * *$} & Go & $196(27)$ & \multirow{2}{*}{$F<1 ; \mathrm{ns}$} \\
\hline & & Adult & $188(47)$ & & No-go & $199(48)$ & \\
\hline \multirow{4}{*}{$\mathbf{N} 2$} & \multirow{2}{*}{ Amp } & Child & $-0.34(0.39)$ & \multirow{2}{*}{$F<1 ;$ ns } & Go & $-0.26(0.50)$ & ค* \\
\hline & & Adult & $-0.34(0.63)$ & & No-go & $-0.42(0.54)$ & ). $2^{*}$ \\
\hline & I ot & Child & $304(40)$ & & Go & $284(44)$ & $F<1 ;$ ns \\
\hline & Lat & Adult & $268(36)$ & & No-go & $288(42)$ & \\
\hline & $\Delta m n$ & Child & $1.02(0.68)$ & & Go & $1.39(0.86)$ & \\
\hline & (1) & Adult & $1.57(0.88)$ & & No-go & $1.20(0.80)$ & \\
\hline & I ot & Child & $517(83)$ & & Go & $488(82)$ & \\
\hline & Eat & Adult & $465(84)$ & $T$ & No-go & 494 (93) & $\Gamma<1,11 \mathrm{~s}$ \\
\hline & $1 \mathrm{mn}$ & Child & $0.24(0.22)$ & & & & \\
\hline & Аापि & Adult & $0.42(0.30)$ & $0.9^{\circ}$ & & & \\
\hline & I. & Child & $324(59)$ & & & & \\
\hline & Lat & Adult & $313(50)$ & 110 & & & \\
\hline
\end{tabular}




\section{Pearson's product moment correlations}

Table 4 shows the results of the Pearson's product moment correlations between behavioral data and corrected ERP components performed separately for children and adults. This statistical analysis yielded no significant results.

Table 4. Pearson's product moment correlations $(r)$ and statistical significance $(p)$ between pre- and poststimulus ERP components and behavioral data. The correlational analyses were performed separately for children and adults.

Adults $(n=18)$

\begin{tabular}{llrrrrrc}
\hline & & $\mathrm{pN} 1 \mathrm{Go}$ & $\mathrm{pP1}$ Go & $\mathrm{pN1}$ No-go & $\mathrm{pP} 1 \mathrm{No}-\mathrm{go}$ & $\mathrm{BP}$ & $\mathrm{pN}$ \\
\hline $\mathrm{RT}$ & $r$ & -0.06 & 0.13 & -0.04 & 0.13 & -0.28 & 0.16 \\
& $p$ & 0.83 & 0.61 & 0.88 & 0.62 & 0.25 & 0.53 \\
\hline $\mathrm{ICV}$ & $r$ & 0.04 & -0.07 & 0.03 & -0.11 & 0.16 & 0.11 \\
& $p$ & 0.61 & 0.79 & 0.71 & 0.65 & 0.54 & 0.65 \\
\hline$\% \mathrm{CE}$ & $r$ & -0.10 & 0.19 & -0.17 & 0.16 & -0.14 & -0.46 \\
& $p$ & 0.25 & 0.45 & 0.17 & 0.51 & 0.57 & 0.85 \\
\hline \%OE & $r$ & 0.20 & -0.18 & 0.25 & -0.25 & 0.09 & 0.20 \\
& $p$ & 0.30 & 0.47 & 0.32 & 0.33 & 0.69 & 0.43 \\
\hline
\end{tabular}

Children $(n=18)$

\begin{tabular}{llcrrrrc}
\hline & & pN1 Go & pP1 Go & pN1 No-go & pP1 No-go & BP & pN \\
\hline RT & $r$ & 0.04 & 0.10 & -0.20 & 0.23 & 0.28 & -0.34 \\
& $p$ & 0.73 & 0.57 & 0.45 & 0.37 & 0.26 & 0.16 \\
\hline ICV & $r$ & -0.01 & 0.33 & 0.07 & 0.06 & 0.32 & 0.29 \\
& $p$ & 0.70 & 0.13 & 0.58 & 0.56 & 0.19 & 0.25 \\
\hline$\%$ CE & $r$ & 0.01 & 0.22 & 0.02 & -0.06 & -0.03 & 0.17 \\
& $p$ & 0.64 & 0.48 & 0.35 & 0.68 & 0.89 & 0.49 \\
\hline$\%$ OE & $r$ & -0.14 & 0.39 & -0.21 & 0.16 & -0.17 & -0.12 \\
& $p$ & 0.58 & 0.09 & 0.41 & 0.56 & 0.49 & 0.64 \\
\hline
\end{tabular}

\section{Discussion}

The present study confirmed that children performance in a visuo-motor DRT was slower and less accurate than adults. This finding can be explained as the correlate of the less intense proactive cognitive 
and motor preparation, as indexed by the $\mathrm{pN}$ and $\mathrm{BP}$ components, respectively. Moreover, children exhibited reduced attentional processing, as revealed by the smaller N1, pP1 and P3 components with respect to adults. More importantly, children showed a less intense evidence accumulation process in the anterior insular cortex, as showed by the reduced dpP2 component.

\section{Behavioral Performance}

Consistently with previous literature (Casey et al., 1997; Ciesielski, Harris, \& Cofer, 2004; Jonkman, Lansbergen, \& Stauder, 2003), in the present study children were less efficient in suppressing unwanted responses compared to adults (higher $\% \mathrm{CE}$ ). Considering that inhibitory control largely relies on the engagement of the prefrontal cortex (Aron, Robbins, \& Poldrack, 2004; Bunge, Dudukovic, Thomason, Vaidya, \& Gabrieli, 2002; Casey et al., 1997), and that this brain region reaches full maturation only in adult age (Bunge, Dudukovic, Thomason, Vaidya, \& Gabrieli, 2002), the poor behavioral performance of children is not surprising. In line with previous studies (Bellgrove, Hester, \& Garavan, 2004), the poor inhibitory control was also associated with low response consistency (high ICV). Since the activity of the prefrontal cortex allows also a more consistent response speed (Bellgrove, Hester, \& Garavan, 2004; Perri, Berchicci, Lucci, Spinelli, \& Di Russo, 2015a), the higher variability observed in children further supports the hypothesis of an immature contribution of the prefrontal cortex. Similarly, the post-error slowing found in adult only confirms the presence of proactive control in adults, but not in children. However, due to the low trials number, the reliability of these measure should be carefully considered.

\section{Pre-stimulus ERP}

The BP emerged earlier in children than adults (Figure 1), suggesting prolonged and less efficient motor preparation within the cingulate and supplementary motor areas, a pattern similar to that of adult nonathletes when compared to élite athletes (Di Russo, Pitzalis, Aprile, \& Spinelli, 2005). Following the BP 
trend, also the pN emerged earlier and was smaller in children than in adults. Since the pN originates from the pars opercularis of the inferior frontal gyrus (BA 44) (Di Russo et al., 2016; Sulpizio et al., 2017), it was proposed to be an index of cognitive preparation (Berchicci, Lucci, Pesce, Spinelli, \& Di Russo, 2012; Di Russo et al., 2016), as also suggested by earlier studies using CNV paradigms (e.g. Cui et al., 2000). However, the $\mathrm{pN}$, particularly in the right hemisphere, seems especially associated with proactive inhibitory control (Bianco, Berchicci, Perri, Quinzi, \& Di Russo, 2017; Bianco, Berchicci, Perri, Spinelli, \& Di Russo, 2017). The earlier pN onset might be explained in the framework of a less efficient cognitive preparation, as already observed by other researches on aging showing larger frontal CNV (Wild-Wall, Hohnsbein, \& Falkenstein, 2007) and pN (Berchicci, Lucci, Pesce, Spinelli, \& Di Russo, 2012) in older people. On the other hand, in the present study lower BP and $\mathrm{pN}$ could be associated with the uncompleted development of the proactive control. 

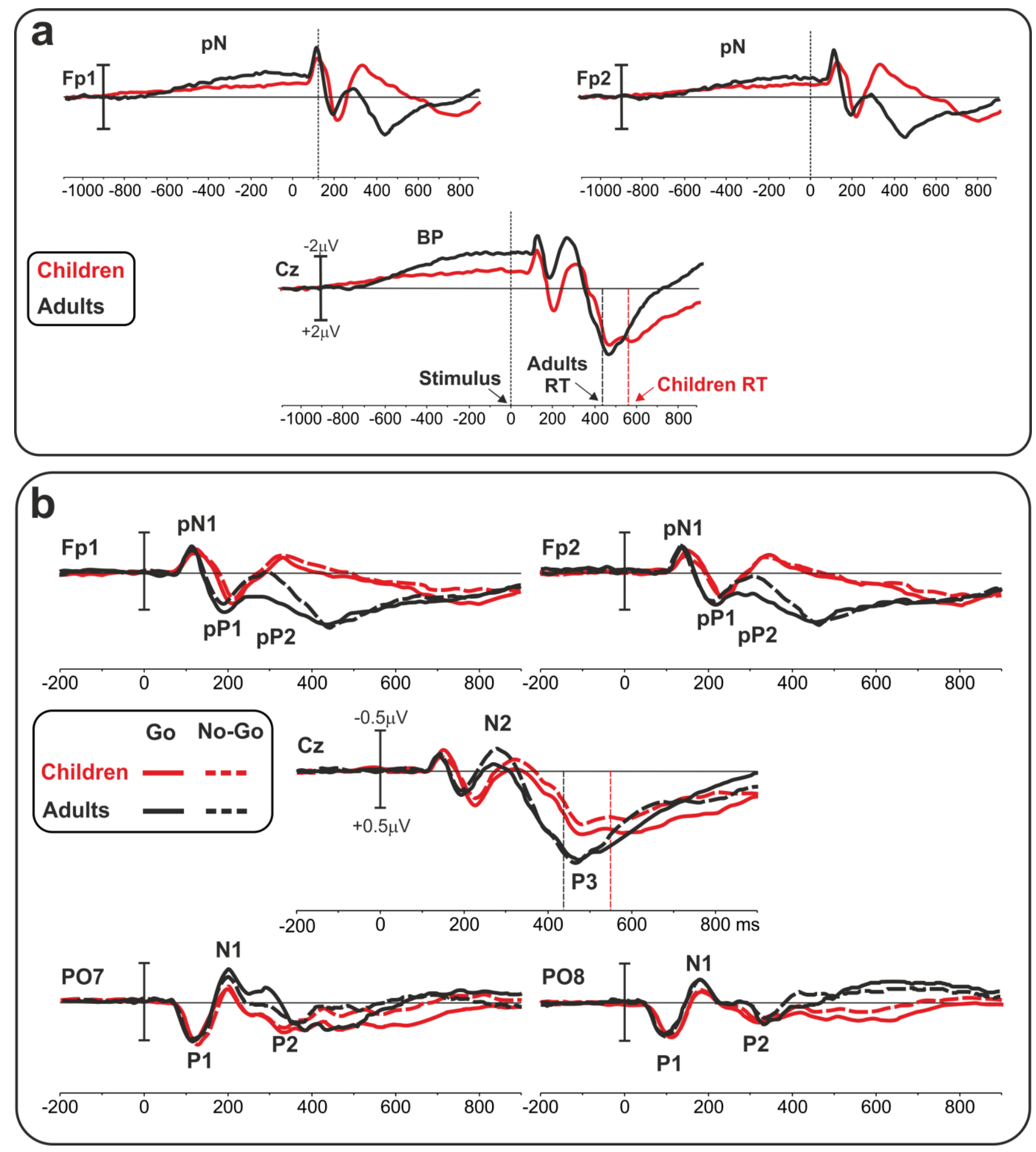

Figure 5 


\section{Post-stimulus ERP}

The post-stimulus components observed over prefrontal sites, i.e. the $\mathrm{pN} 1$ and the $\mathrm{pP} 1$, are consistent with those presented in a previous study of our research group, where we investigated the effect of aerobic fitness on brain health in children (Berchicci et al., 2015). In the present study, children exhibited smaller pN1 and pP1 compared to adults. Moreover, they presented a delayed pP1 with respect to adults. It has been proposed that this component, associated with the activity of the anterior insula, reflects top-down visual processing (Berchicci, Spinelli, \& Di Russo, 2016; Perri, Berchicci, Bianco, Spinelli, \& Di Russo, 2018), including awareness of the sensory-motor integration (Perri et al., 2018). It seems that the topdown visual processing of children requires longer time to be accomplished, explaining, to some extent, the slower RTs observed in this group. The delayed latency of this and other components could be interpreted considering the neuro-anatomical development of the brain, presenting an ongoing myelination process (Barry \& Blasio, 2015; Barry, De Blasio, \& Borchard, 2014; Ciesielski, Harris, \& Cofer, 2004; Giedd et al., 1999; Johnstone et al., 2007; Lamm, Zelazo, \& Lewis, 2006). Compared to adults, children showed reduced attentional processing during both stimulus- and response-evaluation stages, as indexed by the smaller N1 and P3 components.

The subtractive waves allowed isolating the pP2 Go/No-go effect, showing in children a topographical distribution similar to the adults, although their amplitude was lower. This lower activity may likely represent a reduced efficacy of the evidence accumulation process, which may account, along with a reduced attentional processing $(\mathrm{N} 1)$ and sensory awareness (pP1), for the slower and the more errorprone performance observed in children. Indeed, the $\mathrm{pP} 2$ activity was related to stimulus-response mapping process and efficacy of the decision process (Berchicci, Lucci, Perri, Spinelli, \& Di Russo, 2014; Perri, Berchicci, Lucci, Spinelli, \& Di Russo, 2015a, 2016; Perri, Berchicci, Spinelli, \& Di Russo, 2014; Perri \& Di Russo, 2017). Without the subtraction procedure, the pP2 was not visible in children, possibly because of the overlapping negative activity observed over fronto-central sites. Indeed, in the 
same interval, children exhibited a large negativity over frontal-central sites, the frontal N2, which is consistent to previous findings during auditory (Barry \& Blasio, 2015) or visual (Jonkman, Lansbergen, \& Stauder, 2003) Go/No-go tasks. Considering the delayed children RT (ms) and the premotor interpretation of the N2 origin (Di Russo et al., 2016, 2017; Perri, Berchicci, Bianco, Spinelli, \& Di Russo, 2018), the large frontal N2 may represent delayed motor preparation, which reach its peak when the adult response in already emitted.

Some considerations should be taken into account when interpreting present results. First, the absence of information concerning the anatomical and neural maturational status of children, prompts us to interpret cautiously the electrophysiological differences observed between our experimental groups. Second, it may be questioned whether the referencing system adopted in the present (left mastoid) study may have altered the topographical distribution of pre- and post-stimulus ERP components. To unravel any possible bias of the selected reference (left mastoid) we performed additional analysis adopting the average reference. These analyses showed no effect of the reference on the ERP topography (see supplementary Figures 1-3) confirming previous studies indicating that the used reference channel may add or subtract a constant value at all channel locations resulting in a substantially unmodified topography (Yao, 2001; Yao et al 2005, 2007; Tian and Yao, 2013). Third, it could be questioned why the present study failed to show significant correlations between ERPs and behavioral data. A possible explanation of this aspect may be the limited sample size to perform correlation analyses separately for the two groups. Indeed previous studies (Bianco, Berchicci, Perri, Quinzi, \& Di Russo, 2017; Bianco, Di Russo, Perri, \& Berchicci, 2017; Perri, Berchicci, Spinelli, \& Di Russo, 2014) in a larger sample size ( $n>39)$, showed significant correlations between the BP and RTs. On the other hand, a correlation analysis with Children and Adults pooled together may result in significant correlations due to the heterogeneity of the two groups rather than to a functional modulation of a given ERP component. Last the experimental design 
adopted in the present study assumes that the two groups differ only in the maturational status and no other factors influenced their electrophysiological and behavioral performance.

\section{Conclusions}

This is the first ERP study investigating developmental changes during both pre- and post-stimulus stages of cognitive processing during a complex visuo-motor discrimination task. We propose that the larger ERP components commonly observed in children compared to adults should not be interpreted as the sign of enhanced cognitive processes, as demonstrated also by the poor behavioral performance; rather, as revealed by the analysis on the "corrected" data, they appear to represent an EEG epiphenomenon related to the anatomical and neural modifications occurring in developing children. Summarizing, based on the available electrophysiological and behavioral data, we propose that children are characterized by less intense task preparation processes compared to adults, which may account, together with a reduced attentional processing and with a poor sensory awareness, for their inaccurate and slow behavioral performance. Educational and motor programs for preadolescents should consider that their brain is not only immature in proactive prefrontal inhibitory functions but also in motor preparation and in the reactive focus of attention and in the decision-making processes. 


\section{References}

Aron, A., Robbins, T., \& Poldrack, R. (2004). Inhibition and the right inferior frontal cortex. Trends in Cognitive Sciences, 8(4), 170-177. https://doi.org/10.1016/j.tics.2004.02.010

Barry, R. J., \& Blasio, F. M. D. E. (2015). Performance and ERP components in the equiprobable go/no-go task: Inhibition in children. Psychophysiology, 52, 1228-1237. https://doi.org/10.1111/psyp.12447

Barry, R. J., De Blasio, F. M., \& Borchard, J. P. (2014). Sequential processing in the equiprobable auditory Go/NoGo task: Children vs. adults. Clinical Neurophysiology, 125(10), 1995-2006. https://doi.org/10.1016/j.clinph.2014.02.018

Bellgrove, M. A., Hester, R., \& Garavan, H. (2004). The functional neuroanatomical correlates of response variability: Evidence from a response inhibition task. Neuropsychologia, 42(14), 19101916. https://doi.org/10.1016/j.neuropsychologia.2004.05.007

Berchicci, M., Lucci, G., Perri, R. L., Spinelli, D., \& Di Russo, F. (2014). Benefits of physical exercise on basic visuo-motor functions across age. Frontiers in Aging Neuroscience, 6(MAR), 1-8. https://doi.org/10.3389/fnagi.2014.00048

Berchicci, M., Lucci, G., Pesce, C., Spinelli, D., \& Di Russo, F. (2012). Prefrontal hyperactivity in older people during motor planning. NeuroImage, 62(3), 1750-1760.

https://doi.org/10.1016/j.neuroimage.2012.06.031

Berchicci, M., Pontifex, M. B., Drollette, E. S., Pesce, C., Hillman, C. H., \& Di Russo, F. (2015). From cognitive motor preparation to visual processing: The benefits of childhood fitness to brain health. Neuroscience, 298, 211-219. https://doi.org/10.1016/j.neuroscience.2015.04.028

Berchicci, M., Spinelli, D., \& Di Russo, F. (2016). New insights into old waves. Matching stimulusand response-locked ERPs on the same time-window. Biological Psychology, 117(April), 202215. https://doi.org/10.1016/j.biopsycho.2016.04.007

Bianco, V., Berchicci, M., Perri, R. L., Quinzi, F., \& Di Russo, F. (2017). Exercise-related cognitive effects on sensory-motor control in athletes and drummers compared to non-athletes and other musicians. Neuroscience, 360. https://doi.org/10.1016/j.neuroscience.2017.07.059

Bianco, V., Berchicci, M., Perri, R. L., Spinelli, D., \& Di Russo, F. (2017). The proactive self-control of actions: Time-course of underlying brain activities. NeuroImage, 156(December), 388-393. https://doi.org/10.1016/j.neuroimage.2017.05.043

Bianco, V., Di Russo, F., Perri, R. L., \& Berchicci, M. (2017). Different proactive and reactive action control in fencers' and boxers' brain. Neuroscience, 343, 260-268.

https://doi.org/10.1016/j.neuroscience.2016.12.006

Bunge, S. A., Dudukovic, N. M., Thomason, M. E., Vaidya, C. J., \& Gabrieli, J. D. E. (2002).

Immature frontal lobe contributions to cognitive control in children: evidence from fMRI. Neuron, 33(2), 301-311.

Casey, B. J., Trainor, R. J., Orendi, J. L., Schubert, A. B., Nystrom, L. E., Giedd, J. N., ... Rapoport, J. L. (1997). A Developmental Functional MRI Study of Prefrontal Activation during Performance of a Go-No-Go Task. Journal of Cognitive Neuroscience, 9(6), 835-847. 
https://doi.org/10.1162/jocn.1997.9.6.835

Ciesielski, K. T., Harris, R. J., \& Cofer, L. F. (2004). Posterior brain ERP patterns related to the go/nogo task in children. Psychophysiology, 41(6), 882-892. https://doi.org/10.1111/j.14698986.2004.00250.x

Cui, R. Q., Egkher, A., Huter, D., Lang, W., Lindinger, G., \& Deecke, L. (2000). High resolution spatiotemporal analysis of the contingent negative variation in simple or complex motor tasks and a non-motor task. Clinical Neurophysiology : Official Journal of the International Federation of Clinical Neurophysiology, 111(10), 1847-1859.

Darriba, Á., \& Waszak, F. (2018). Predictions through evidence accumulation over time. Scientific Reports, 8(1), 1-15. https://doi.org/10.1038/s41598-017-18802-z

Davidson, M. C., Amso, D., Cruess Anderson, L., \& Diamond, A. (2006). Development of cognitive control and executive functions from 4 to 13 years: Evidence from manipulations of memory, inhibition, and task switching. Neuropsychologia, 44(11), 2037-2078. https://doi.org/10.1097/MPG.0b013e3181a15ae8.Screening

Davis, E. P., Bruce, J., Snyder, K., \& Nelson, C. A. (2003). The X-Trials: Neural Correlates of an Inhibitory Control Task in Children and Adults. Journal of Cognitive Neuroscience, 15(3), 432443. https://doi.org/10.1162/089892903321593144

Deoni, S. C. L., Dean, D. C., Remer, J., Dirks, H., \& O’Muircheartaigh, J. (2015). Cortical maturation and myelination in healthy toddlers and young children. NeuroImage, 115, 147-161. https://doi.org/10.1016/j.neuroimage.2015.04.058

Di Rollo, A., Cosottini, M., Pesaresi, I., Fabbri, S., Di Russo, F., Perri, R. L., ... Sartucci, F. (2016). 29. ERP generators in an omitted-target oddball task: A simultaneous EEG-fMRI study. Clinical Neurophysiology, 127(12), e330. https://doi.org/10.1016/j.clinph.2016.10.041

Di Russo, F., Berchicci, M., Bozzacchi, C., Perri, R. L., Pitzalis, S., \& Spinelli, D. (2017). Beyond the "Bereitschaftspotential": Action preparation behind cognitive functions. Neuroscience and Biobehavioral Reviews, 78(April), 57-81. https://doi.org/10.1016/j.neubiorev.2017.04.019

Di Russo, F., Lucci, G., Sulpizio, V., Berchicci, M., Spinelli, D., Pitzalis, S., \& Galati, G. (2016). Spatiotemporal brain mapping during preparation, perception, and action. NeuroImage, 126, 1-14. https://doi.org/10.1016/j.neuroimage.2015.11.036

Di Russo, F., Pitzalis, S., Aprile, T., \& Spinelli, D. (2005). Effect of practice on brain activity: An investigation in top-level rifle shooters. Medicine and Science in Sports and Exercise, 37(9), 1586-1593. https://doi.org/10.1249/01.mss.0000177458.71676.0d

Diamond, A. (1988). Abilities and neural mechanisms underlying AB performance. Child Development, 59(2), 523-527. https://doi.org/10.2307/1130330

Diamond, A. (2002). Normal development of prefrontal cortex from birth to young adulthood: cognitive functions, anatomy and biochemistry. In D. T. Stuss \& R. T. Knight (Eds.), Principles of frontal lobe function (pp. 466-503). New York: Oford University Press. https://doi.org/10.1093/acprof

Falkenstein, M., Hoormann, J., \& Hohnsbein, J. (1999). ERP components in Go/Nogo tasks and their relation to inhibition. Acta Psychologica, 101(2-3), 267-291. https://doi.org/10.1016/S0001- 
6918(99)00008-6

Foxe, J. J., \& Simpson, G. V. (2002). Flow of activation from V1 to frontal cortex in humans. A framework for defining "early" visual processing. Experimental Brain Research, 142(1), 139150. https://doi.org/10.1007/s00221-001-0906-7

Friedman, D., Nessler, D., Cycowicz, Y. M., \& Horton, C. (2009). Development of and change in cognitive control: A comparison af children, young and older adults. Cognitive Affective Behavioral Neuroscience, 9(1), 152-170. https://doi.org/10.3758/CABN.9.1.91.Development

Giedd, J. A. Y. N., Blumenthal, J., Jeffries, N., Rajapakse, J. C., Vaituzis, A. C., Liu, H., ... Castellanos, F. X. (1999). Development of the human corpus callosum during childhood and adolescence: a logitudinal MRI study. Progress in Neuro-Psychoparmacol and Biological Psychiatry, 23, 571-588.

Holcomb, P. J., Coffey, S., \& Neville, H. (1992). Visual and auditory sentence processing: A developmental analysis using event-related brain potentials. Developmental Neuropsychology, 8(2-3), 203-241. https://doi.org/10.1080/87565649209540525

Huttenlocher, P. (1979). Synaptic density in human frontal cortex - Developmental changes and effects of aging. Brain Research, 163(2), 195-205. https://doi.org/10.1016/0006-8993(79)90349-4

Johnstone, S. J., Dimoska, A., Smith, J. L., Barry, R. J., Pleffer, C. B., Chiswick, D., \& Clarke, A. R. (2007). The development of stop-signal and Go/Nogo response inhibition in children aged 712??years: Performance and event-related potential indices. International Journal of Psychophysiology, 63(1), 25-38. https://doi.org/10.1016/j.ijpsycho.2006.07.001

Jonkman, L. M. (2006). The development of preparation, conflict monitoring and inhibition from early childhood to young adulthood; a Go/Nogo ERP study. Brain Research, 1097(1), 181-193. https://doi.org/10.1016/j.brainres.2006.04.064

Jonkman, L. M., Lansbergen, M., \& Stauder, J. E. A. (2003). Developmental differences in behavioral and event- related brain responses associated with response preparation and inhibition in a go / nogo task. Psychophysiology, 40, 752-761.

Knott, P. D., Hazony, D., Karafa, M., \& Koltai, P. J. (2004). High-frequency ultrasound in the measurement of pediatric craniofacial integrity. Otolaryngology - Head and Neck Surgery, 131(6), 851-855. https://doi.org/10.1016/j.otohns.2004.08.010

Lamm, C., Zelazo, P. D., \& Lewis, M. D. (2006). Neural correlates of cognitive control in childhood and adolescence: Disentangling the contributions of age and executive function.

Neuropsychologia, 44(11), 2139-2148. https://doi.org/10.1016/j.neuropsychologia.2005.10.013

Luna, B., Thulborn, K. R., Munoz, D. P., Merriam, E. P., Garver, K. E., Minshew, N. J., ... Sweeney, J. A. (2001). Maturation of widely distributed brain function subserves cognitive development. NeuroImage, 13(5), 786-793. https://doi.org/10.1006/nimg.2000.0743

Okazaki, S., Hosokawa, M., Kawakubo, Y., Ozaki, H., Maekawa, H., \& Futakami, S. (2004). Developmental change of neurocognitive motor behavior in a continuous performance test with different interstimulus intervals. Clinical Neurophysiology, 115(5), 1104-1113. https://doi.org/10.1016/j.clinph.2003.12.021

Perri, R. L., Berchicci, M., Bianco, V., Quinzi, F., Spinelli, D., \& Di Russo, F. (2018). Endogenous 
Visual Processing Associated to Perceptual Analysis within the Anterior Insula, in press.

Perri, R. L., Berchicci, M., Bianco, V., Spinelli, D., \& Di Russo, F. (2018). Brain waves from an "isolated" cortex: contribution of the anterior insula to cognitive functions. Brain Structure \& Function, 223(3), 1343-1355. https://doi.org/10.1007/s00429-017-1560-6

Perri, R. L., Berchicci, M., Lucci, G., Spinelli, D., \& Di Russo, F. (2015a). The premotor role of the prefrontal cortex in response consistency. Neuropsychology, 29(5), 767-775. https://doi.org/10.1037/neu0000168

Perri, R. L., Berchicci, M., Lucci, G., Spinelli, D., \& Di Russo, F. (2015b). Why do we make mistakes? Neurocognitive processes during the preparation-perception-action cycle and error-detection. NeuroImage, 113, 320-328. https://doi.org/10.1016/j.neuroimage.2015.03.040

Perri, R. L., Berchicci, M., Lucci, G., Spinelli, D., \& Di Russo, F. (2016). How the brain prevents a second error in a perceptual decision- making task. Nature Publishing Group, (August), 1-11. https://doi.org/10.1038/srep32058

Perri, R. L., Berchicci, M., Spinelli, D., \& Di Russo, F. (2014). Individual differences in response speed and accuracy are associated to specific brain activities of two interacting systems. Frontiers in Behavioral Neuroscience, 8(July), 251. https://doi.org/10.3389/fnbeh.2014.00251

Perri, R. L., \& Di Russo, F. (2017). Executive Functions and Performance Variability Measured by Event-Related Potentials to Understand the Neural Bases of Perceptual Decision-Making. Frontiers in Human Neuroscience, 11(November), 1-5. https://doi.org/10.3389/fnhum.2017.00556

Polich, J. (2007). Updating P300: An integrative theory of P3a and P3b. Clinical Neurphysiology, 118(10), 2128-2148. https://doi.org/10.1016/j.clinph.2007.04.019

Potts, G. F., Liotti, M., Tucker, D. M., \& Posner, M. I. (1996). Frontal and inferior temporal cortical activity in visual target detection: Evindence from high spatially sampled event-realated potentials. Brain Topography, 9(1), 3-14.

Sanchez-Lopez, J., Pedersini, C. A., Di Russo, F., Cardobi, N., Fonte, C., Varalta, V., ... Marzi, C. A. (2017). Visually evoked responses from the blind field of hemianopic patients. Neuropsychologia, (August), 1-13. https://doi.org/10.1016/j.neuropsychologia.2017.10.008

Segalowitz, S. J., Santesso, D. L., \& Jetha, M. K. (2010). Electrophysiological changes during adolescence: A review. Brain and Cognition, 72(1), 86-100.

https://doi.org/10.1016/j.bandc.2009.10.003

Shibasaki, H., \& Hallett, M. (2006). What is the Bereitschaftspotential? Clinical Neurophysiology, 117(11), 2341-2356. https://doi.org/10.1016/j.clinph.2006.04.025

Sowell, E. R. (2004). Longitudinal Mapping of Cortical Thickness and Brain Growth in Normal Children. Journal of Neuroscience, 24(38), 8223-8231. https://doi.org/10.1523/JNEUROSCI.1798-04.2004

Sowell, E. R., Delis, D., Stiles, J., \& Jernigan, T. L. (2001). Improved memory funct ioning and frontal lobe maturation between childhood and adolescence: a structural MRI study. Journal of the International Neuropsychological Society: JINS, 7(3), 312-322. https://doi.org/10.1017/S135561770173305X 
Sulpizio, V., Lucci, G., Berchicci, M., Galati, G., Pitzalis, S., \& Di Russo, F. (2017). Hemispheric asymmetries in the transition from action preparation to execution. NeuroImage, 148, 390-402. https://doi.org/10.1016/j.neuroimage.2017.01.009

Tian, Y., and Yao, D. (2013). Why do we need to use a zero reference? Reference influences on the ERPs of audiovisual effects. Psychophysiology, 50(12), 1282-90

Vidal, J., Mills, T., Pang, E. W., \& Taylor, M. J. (2012). Response inhibition in adults and teenagers: Spatiotemporal differences in the prefrontal cortex. Brain and Cognition, 79(1), 49-59. https://doi.org/10.1016/j.bandc.2011.12.011

VijayaKumar, N., Whittle, S., Yucel, M., Dennison, M., Simmons, J., \& Allen, N. B. (2014). Prefrontal Structural correlates of cognitive control during adolescent development: a 4- year longitudinal study. Journal of Cognitive Neuroscience, 26(5), 1118-1130. https://doi.org/10.1162/jocn

Wild-Wall, N., Hohnsbein, J., \& Falkenstein, M. (2007). Effects of ageing on cognitive task preparation as reflected by event-related potentials. Clinical Neurophysiology, 118(3), 558-569. https://doi.org/10.1016/j.clinph.2006.09.005.

Yao, D., Wang, L., Robert Oostenveld, R, Dremstrup Nielsen, K, Arendt-Nielsen L and CN Chen A (2005). A comparative study of different references for EEG spectral mapping: the issue of the neutral reference and the use of the infinity reference. Physiol. Meas. 26, 1-12.

Yao, D. (2001). A method to standardize a reference of scalp EEG recordings to a point at infinity. Physiol. Meas. 22, 693-711.

Yao, D., Wang, L., Arendt-Nielsen, L., CN Chen, A. (2007). The effect of reference choices on the spatio-temporal analysis of brain evoked potentials: The use of infinite reference. Computers in Biology and Medicine 37, 1529 - 1538. 


\section{Figure Captions}

Figure 1. (a) Pre-stimulus ERPs components (BP and pN) for children (red lines) and adults (black lines). (b) Topographical distribution of the original ERPs for children (upper part) and adults (lower part) in the three intervals considered for statistical analysis.

Figure 2. Post-stimulus ERPs components for children (red lines) and adults (black lines) for Go (solid lines) and No-go (dashed lines) trials.

Figure 3. Topographical maps of post-stimulus ERP components for Go (a) and No-go (b) trials for adults and children.

Figure 4. (a) Go minus No-go corrected differential waveforms of children and adults are presented in red and black lines respectively. (b) Differential-waves topographical maps in two intervals of interest.

Figure 5. Post-stimulus corrected ERPs components for children (red lines) and adults (black lines) for Go (solid lines) and No-go (dashed lines) trials.

Supplementary Figure 1. Comparison of average reference and left mastoid reference on the topography of the early prefrontal (pN1 and pP1) and occipital (P1 and N1) ERP components in children and adults (upper and lower maps, respectively). As it can be noticed in both groups, the topographical distribution of these potentials is not affected by the reference.

Supplementary Figure 2. Comparison of average and left mastoid reference on the ERP waveforms at prefrontal electrodes (Fp1, in blue and Fp2 in red) for children and adults. Compared to the left mastoid reference, the average reference results in an overall reduction of the amplitudes of the waveforms. Notwithstanding this aspect, no effect of lateralization can be observed between the two references as depicted by the subtractive wave (black line - Fp2-Fp1).

Supplementary Figure 3. Comparison of average and left mastoid reference on the topography of prestimulus ERP components (BP and $\mathrm{pN}$ ) in children and adults (upper and lower maps, respectively). As it can be noticed in both groups, the topographical distribution of these potentials is not affected by the reference. However, the adoption of the average reference seems to reduce the amplitude of the preparatory activities ( $\mathrm{BP}$ and $\mathrm{pN}$ ) enhancing their positive counterparts (the positive pole of the dipole generating the $\mathrm{pN}$ and the $\mathrm{BP}$ ). 

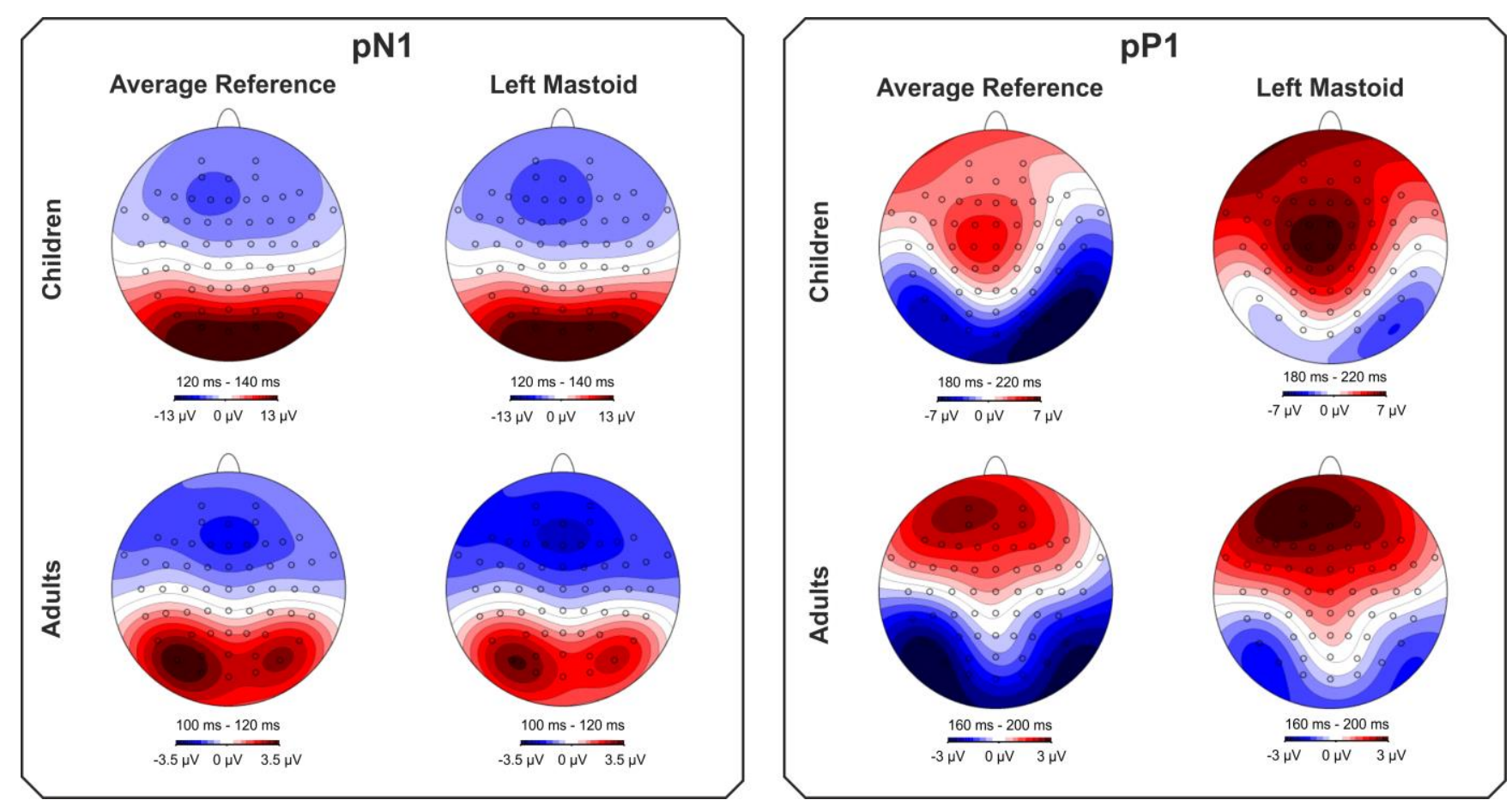

\section{Supplementary Figure 1}




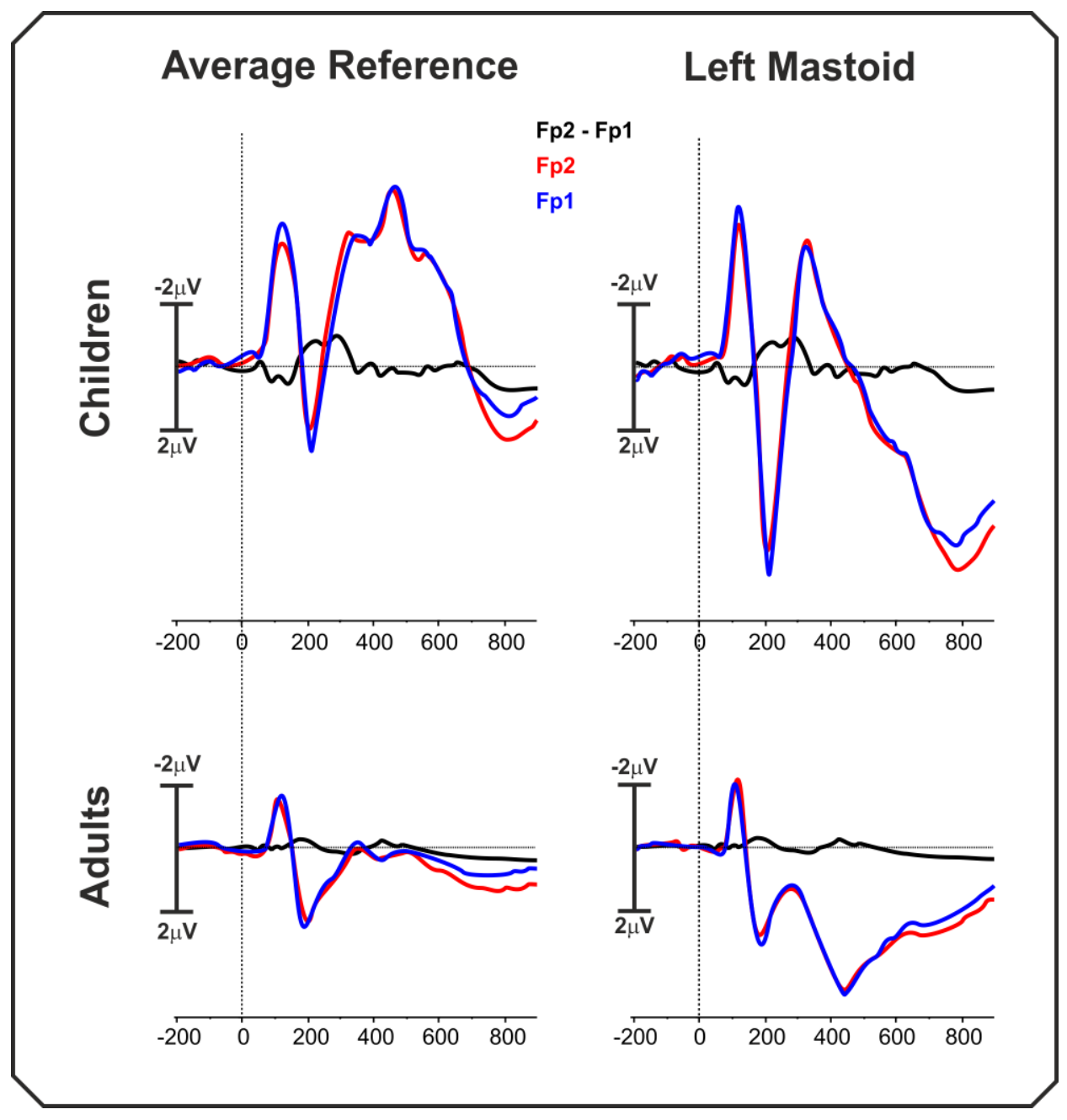

Supplementary Figure 2

36 


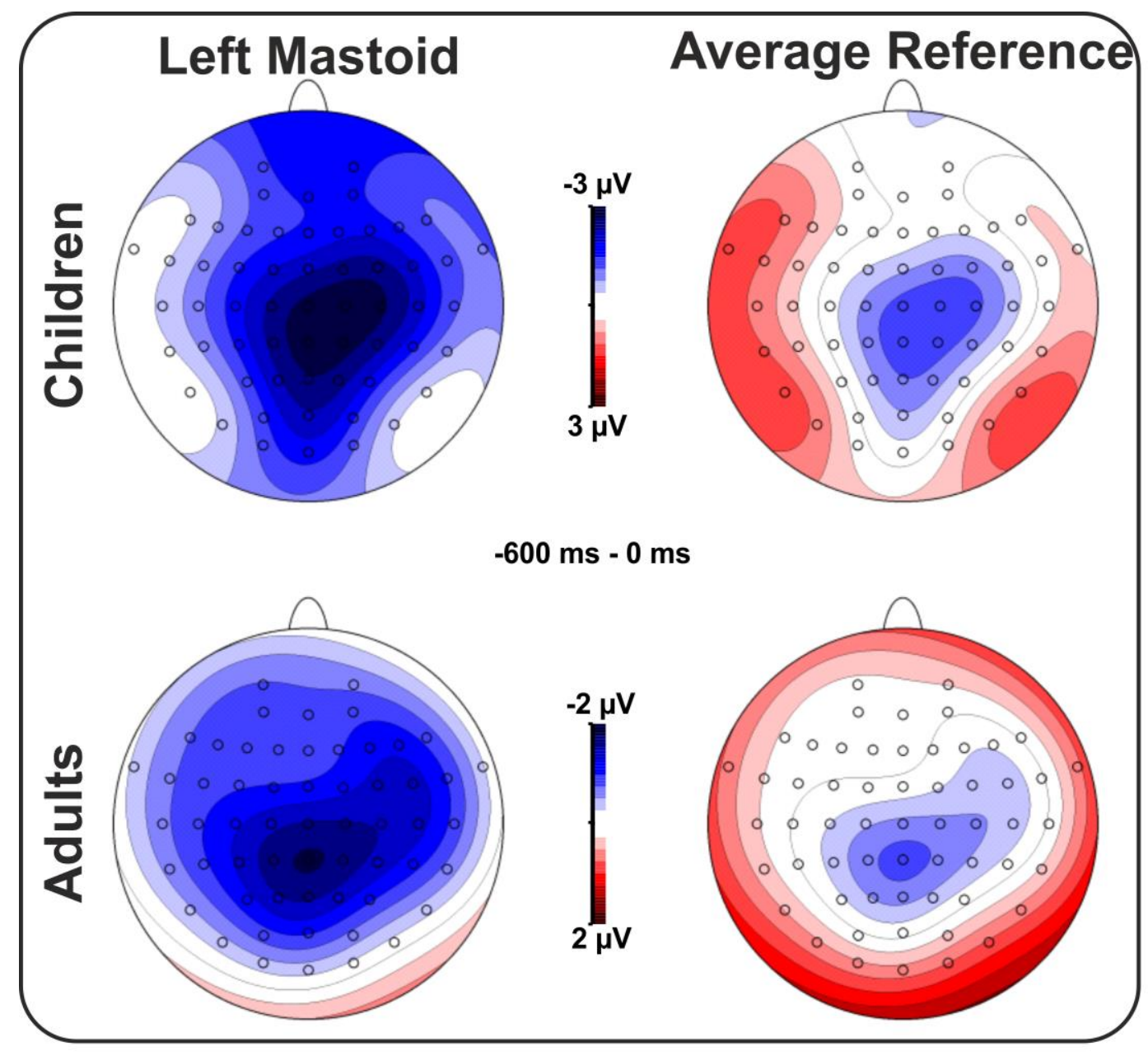

Supplementary Figure 3 